\title{
Caracterização espectroscópica de híbridos plasmon-molécula
}

\author{
René Nome (PQ), Jonas Pinheiro Amato (IC).
}

\section{Resumo}

No presente trabalho foram utilizados nanofios metálicos de prata, dopados em matrizes poliméricas com o intuito de caracterizar o acoplamento de sondas orgânicas fluorescentes, tal acoplamento é realizado pela síntese de filmes finos contendo os nanofios e corantes fluorescentes, como por exemplo a rodamina b e a fluoresceína, em seguida tais filmes são investigados espectroscopicamente pelo mapeamento dos campos evanescentes por microscopia de epifluorescencia, com a intenção de comparar o feito de nanofios de prata em relação a nanoparticulas de prata e ouro já estudados anteriormente.

Palavras Chave: espectroscopia,fluorescência,nanopartículas.

\section{Introdução}

Normalmente, a espectroscopia é realizada em condições de "onda contínua", em que o comprimento de onda da radiação incidente tem largura de banda muito mais fina do que a largura a meia altura de transições moleculares eletrônicas em fases condensadas. Em tais condições, a fase espectral da radiação é constante e observa-se uma relação linear entre a velocidade do grupo de radiação incidente e o tempo de emissão do sinal molecular. Essa é a condição mais comum em espectroscopia, formando a base conceitual para a derivação da lei de Lambert-Beer, por exemplo.

Por outro lado, quando a largura de banda da radiação incidente é muito maior do que a largura a meia altura da transição espectroscópica, observam-se efeitos ressonantes e nãoressonantes mesmo na espectroscopia linear. Isso é comumente observado em espectroscopia de femtosegundos, em que a curta duração resulta em amplo conteúdo espectral, algumas vezes até mais amplo do que a própria transição espectral em estudo.

\section{Resultados e Discussão}

A primeira parte do trabalho se concentrou em caracterizações dos nanofios de prata, fazendo estudos envolvendo o tamanho dos fios, absorbância, e fluorescência, em seguida a busca pela sonda (corante) adequada, e por final a síntese e caracterização dos filmes.

Os filmes foram feitos utilizando a matriz de PMMA, usando o método "casting" onde a matriz é dissolvida em um solvente de rápido evaporação como o THF, o principal resultado está na imagem obtida no microscópio confocal, onde é possível ver um filme contendo nanofio de prata junto com o corente fluoresceína, demonstrado na figura 1 abaixo.

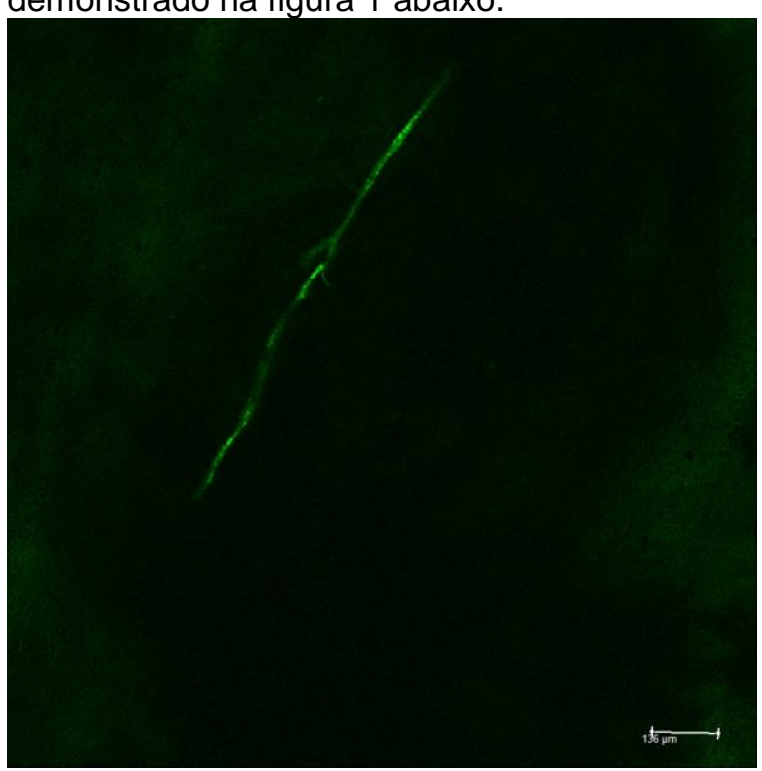

Figura 1. Emissão de nanofio de prata em filme de PMMA.

\section{Conclusões}

Até o presente momento pode-se concluir, que a caracterização foi facilitada devido a presenção de nanofios, pelo fato de possuírem maior tamanho em relação as nanopartículas pesquisadas anteriormente, porém ainda não foi possível averiguar a ausência do efeito de "fotobranqueamento", já observado para as outras nanopartículas.

\section{Agradecimentos}

Agradeço ao CNPq, e a UNICAMP pela oportunidade e também ao meu orientador Rene Nome. 